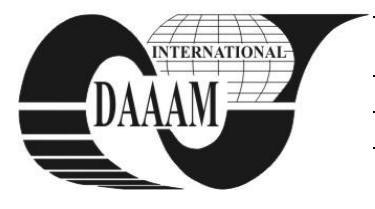

Annals of DAAAM for 2012 \& Proceedings of the 23rd International DAAAM Symposium, Volume 23, No.1, ISSN 2304-1382 ISBN 978-3-901509-91-9, CDROM version, Ed. B. Katalinic, Published by DAAAM International, Vienna, Austria, EU, 2012 Make Harmony between Technology and Nature, and Your Mind will Fly Free as a Bird Annals \& Proceedings of DAAAM International 2012

\title{
SUPPORT AND DIAGNOSTIC SYSTEM FOR DRUM TYPE CHEEPER MACHINES
}

\author{
ZARINS, M[arcis]; TORIMS, T[oms]; MARIS, B[umanis] \& ANDRIS, C[amans]
}

\begin{abstract}
This paper is the second in a series that describes the progress of work on a PhD thesis. The present paper focuses specifically on a waste wood chipping machine, its construction and working principle. The main problems are discussed as well as up-to-date technical improvements and optimization. It also describes the essential, characteristic parameters of the cutting regimes in the cheeping process. As a result, it has been established that the distance between the knives and counter knives is a cyclic variable, caused by cutting force-induced counter knife vibrations.

A brief insight is given into the influence of vibration on cutting regimes. In the conclusion, further steps towards minimizing counter knife vibration are offered. Subsequent research is described, aimed at developing comprehensive diagnostic methods for wood cheeping machines.
\end{abstract}

Keywords: Wood, waste, chipping, diagnostics, maintenance

\section{INTRODUCTION}

This paper is based on the dissertation and research conducted during preparatory phase. In this second paper, we describe the problem presented in the dissertation and set out an attainable target, along with an overview of the research process to date.

In the current, complex economic situation, employers are forced to optimize manufacturing processes so as to reduce the prime cost of goods, in order to survive and remain profitable. One way to achieve savings is through optimal manufacturing facility maintenance and repair.

By modelling a modern, well thought-out manufacturing facility service, based on research and diagnostics, it is possible to reduce emergency stoppages and the consumption of spare parts. A diagnostics model of junction conditions can be developed by establishing a cyclic measurement series and analyzing the results. In this way, the exact point at which expenditure on complementary parts is necessary can be identified and acted upon before its consequences become destructive.

The present research has been carried out in cooperation with Latvian Leveer, Ltd., the leading wood further processing company in Latvia, which has a very large number of manufacturing facilities at its disposal.

All of these facilities require constant maintenance and repair, which usually incurs significant financial investments. Furthermore, sudden stoppages of manufacturing facilities for unscheduled repairs lead to significant losses. The subject of the current research is the investigation and analysis of a wood wastage chipping machine. To date, the setup has been carefully studied and its working principle and analysis have been completed. Thus the main problems and their probable causes have been identified.

The main problem at the present moment is the alteration of the gap between the knife and counter knife, as a result of their wear. Another reason for the altered cutting force is counter knife vibration, whose amplitude is closely correlated to the knife wear process.

This paper presents the experimental results which demonstrate knife wear intensity in a two-week service cycle.

The conclusion is that the service cycle implemented until now is inappropriate and we also detected counter knife holder deflection, owing to the influence of cutting forces. It has also been found that the same cutting forces cause counter knife vibrations that impair the cutting process.

Based on the problems described above, at the end of this paper we describe the hydraulic supporting system, whose task will be to support the middle of the counter knife holder and collect information about pressure variations, from which conclusions may be drawn concerning increased cutting forces.

The work accomplished so far provides a basis for further study, to select the measuring instruments and methodology, as well as to develop a common servicing system.

\section{PROBLEM STATEMENTS}

At this point, we have defined several problems related to the plant operation process.

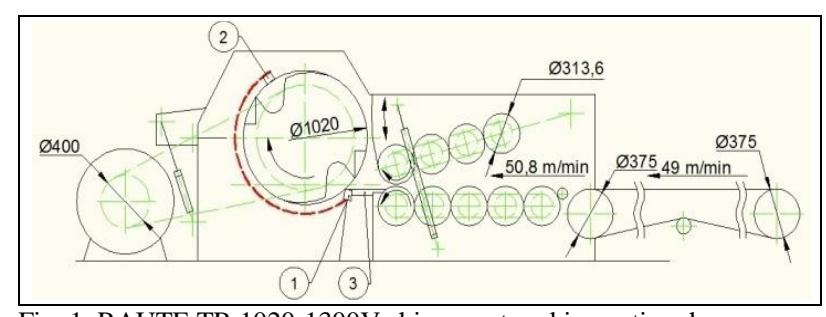

Fig. 1. RAUTE TR 1020-1300V chipper setup, kinematic scheme.

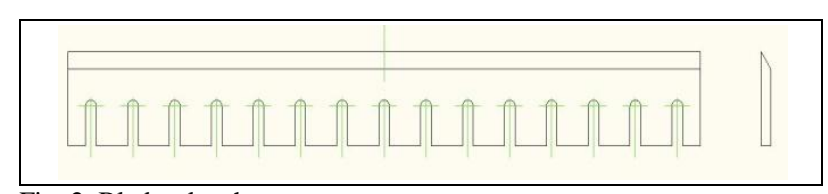

Fig. 2. Blade, sketch. 
These are mostly connected with high dynamic loads, which occur at junctions during chipping machine operation. In particular, the main problems are as follows:

o cyclic squirm of the front of the counter knife (fig.1.,10) during the processing phase;

$\circ$ deformation of the rear of the counter knife (fig.1.,13);

○ stowage of the forward lead-in plate (fig.1, 14) fixation screws and working blade wear (fig.2).

In this paper, we shall focus on the counter knife construction and fastening, together with a description of the delivered force to both.

As a result of the impact initiated by the blade when wood chip is chopped from the whole chipping mass, the load is delivered to the first supporting blade. The load is sufficient to squirm the counter knife housing. Furthermore, these deformations are closely correlated to knife and counter knife wear. The reason is that as the resultant force received by the counter knife alters its direction, so the resultant force value increases.

This leads to a gradual increase in the deflection level of the counter knife and its support (fig.3), which results in permanent physical deformation in the counter knife support [1].

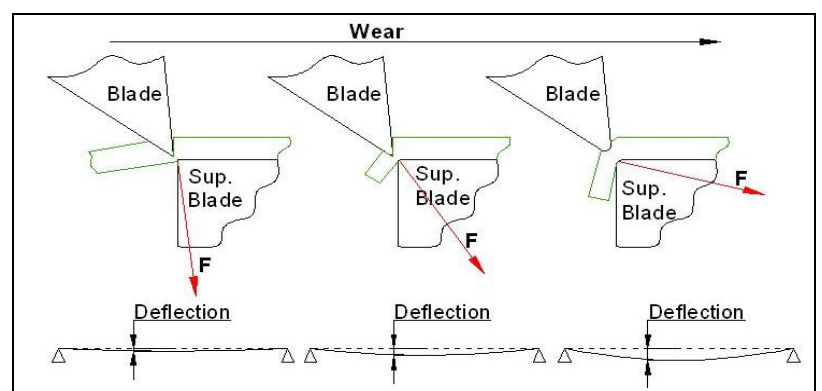

Fig. 3. Deflection of supporting blade.

This kind of deflection creates a wider gap between the knife and counter knife, which changes the cutting mode conditions. The counter knife is being pushed back most markedly in the middle part of the setup, thus this is where cutting process is most impaired. Therefore the forces required in the schredding process also increase. The cutting forces suggest that counter knife deflection is cyclic.

The cutting force frequency can be calculated using formula 1:

$$
F=\frac{z \cdot n}{60} \rightarrow \frac{3 \cdot 556}{60}=27.8 \mathrm{~Hz}
$$

where:

$\mathrm{Z}=$ number of rotor teeth

$\mathrm{n}=$ rotor revolution count

It is evident from the alculations that the basic oscillation/vibration frequency is $27.8 \mathrm{~Hz}$.

Oscillation amplitude depends on several factors: the amount of in-coming shredding material at any given moment, counter knife support rigidity, etc., thus making the frequency very complicated to calculate [2]. To avoid inaccuracies owing to the number of variables, this frequency will not be used for the moment.

During the regulating process, the gap between the counter knife and knife must be set to between 0.4$0.7 \mathrm{~mm}$. As the counter knife housing is deformed, it becomes impossible to set the correct distance.

If the gap is set in the middle, the edges of blade enter the rotating blades operation zone; but if the blades are regulated at the ends, the middle gap becomes too large for the assumed standard. Using a squirmed supporting blade in the cutting process leads to increased loads in the working area and the wood chip quality decreases.

To prevent the described squirm, it is planned to introduce a hydraulic support in the middle part of counter knife holder. Currently a two-week working cycle is common practice, after which the knives are replaced by re-sharpened ones.

This service model is accepted and implemented without any theoretical justification, there are no experimental results to affirm or refute the need for this service cycle model. Research is being carried out and the initial results are already available.

The results demonstrate that the reason for counter knife squirm is inadequate fastening methodology. The knife support is a $1500 \mathrm{~mm}$ long quadratic-shaped bar with a milled seat at one end tailored to the counter knife (fig.4).

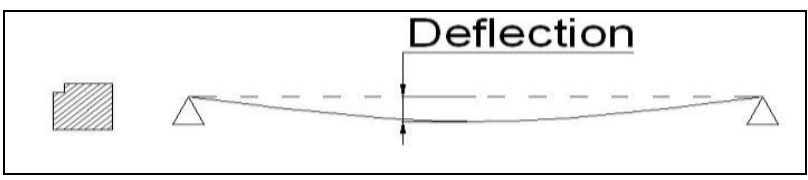

Fig.4. Counter knife support and corresponding fastening scheme

Figure 4 illustrates how the fastening scheme can very easily oscillate under the influence of cutting forces. This is the main problem which will be thoroughly investigated and hopefully eliminated.

The combined range of problems brings about an increase in cyclic loads. This also increases the load on the main engine. As a result, there have been a number of cases of main engine overload and even fires.

\section{DATA OUTPUT}

The working process, describing all the parameters, was summarized so as to be able to perform any kind of analysis and calculation. Some of these parameters have been altered in order to find precise values, and direct measurements have been taken. The main parameters and changes between factory data and real setup working values are given in table 1 . The table data from reference [3]

\begin{tabular}{|l|l|l|}
\hline Parameter & Factory data & Actual data \\
\hline Rotora diameter $(\mathrm{mm})$ & 1020 & 1020 \\
\hline Feed roll diameter $(\mathrm{mm})$ & 313.6 & 313.6 \\
\hline Rotora revolutions $(\mathrm{rmp})$ & 493 & 556 \\
\hline Supply speed $(\mathrm{m} / \mathrm{min})$ & 50 & 44 \\
\hline Number of blades & 2 & 3 \\
\hline $\begin{array}{l}\text { Input hatch dimensions } \\
(\mathrm{mm})\end{array}$ & $1310 \times 375$ & $1310 \times 375$ \\
\hline Main engine power $(\mathrm{kW})$ & 200 & 200 \\
\hline Main engine rev. $(\mathrm{rmp})$ & 1000 & 1000 \\
\hline
\end{tabular}

Table 1. Cheeper machine main parameters. 


\section{RESULTS}

At the present stage, a series of constructional and technological improvements have been implemented with the aim of enhancing the wood shredder's performance. It was also necessary to reduce the size of the wood chips, which were initially significantly larger than the standard size.

The construction of the main rotor was modified in order to reduce wood chip length, namely, a two-knife rotor was substituted by a three-knife rotor (fig.4).

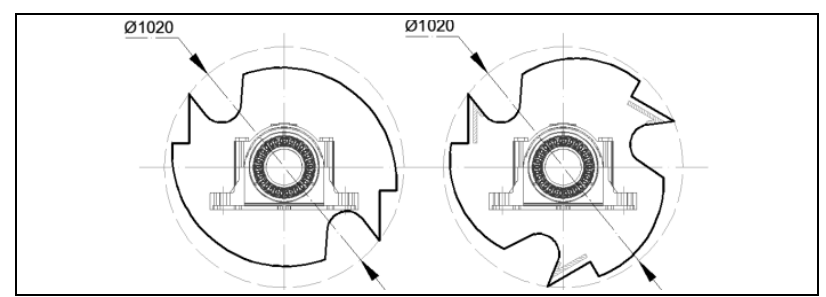

Fig. 5. Old and new type of rotor

Following recommendations [4], the rotor revolution count was increased from 493rmp to 556rmp. Accordingly, both the cutting speed and logging cycle per minute increased.

- Cutting speed

$$
v=\frac{\pi \cdot D \cdot n}{100}
$$

where:

$\mathrm{D}=$ rotor diameter

$\mathrm{n}=$ rotor revolution count per minute

$v_{\text {original }}=\frac{\pi \cdot 1020 \cdot 493}{1000}=1580 \mathrm{~m} / \mathrm{min}$

$v_{\text {real }}=\frac{\pi \cdot 1020 \cdot 556}{1000}=1782 \mathrm{~m} / \mathrm{min}$

It is clearly seen that the increase in the rotor revolution count leads to a cutting speed increase of approx. $12 \%$.

\section{- Supply speed on the tooth}

Supply speed on the tooth depends on the supply speed in one minute, which has been changed from the initial $50 \mathrm{~m} / \mathrm{min}$ to $44 \mathrm{~m} / \mathrm{min}$, as well as the number of teeth on the rotor, which has been changed from 2 to 3 teeth.

$$
S_{z}=\frac{S_{m}}{n \cdot z}
$$

where:

$\mathrm{Sm}=$ supply speed in one minute

$\mathrm{z}=$ number of teeth

$$
\begin{aligned}
& S_{z \text { original }}=\frac{50}{493 \cdot 2}=0,051 \mathrm{~m} / \mathrm{z} \rightarrow 51 \mathrm{~mm} / \mathrm{z} \\
& S_{z \text { real }}=\frac{44}{556 \cdot 3}=0,026 \mathrm{~m} / \mathrm{z} \rightarrow 26 \mathrm{~mm} / \mathrm{z}
\end{aligned}
$$

After making the described adjustments, the recommended wood chip length of $20-30 \mathrm{~mm}$ was achieved. The supply feed on one tooth has reduced by $51 \%$. The aforementioned amendments have reduced overall load on the shredder's electromotor, as the filling of the area between the sieve and the rotor reduces.

In future, cutting force calculations will be performed based on actual experimental results. The results are not yet summarized, as the experimental process has not yet been concluded.

Measurements are being performed on a daily basis; they reflect the changing relationship between the blade and supporting blade during wood cheeping operation. Measurements are taken once a day to monitor the gap between the blade and supporting blade at three points A, B, C (fig.7). These values track the progress of supporting blade squirm along with the overall knife and counter knife wear. Five two-week working cycles have been monitored, and a summary of the results is given in figure 6 . We can conclude that the overall wear of knives and counter knives is significantly greater than expected [4]. However, these results do not tell us about the cyclic deformation of counter knives which occurs in frames with a certain physical elasticity. During the experimental process, we established that these deformations are greater than a permanent deformation and have considerable impact on the shredding process.

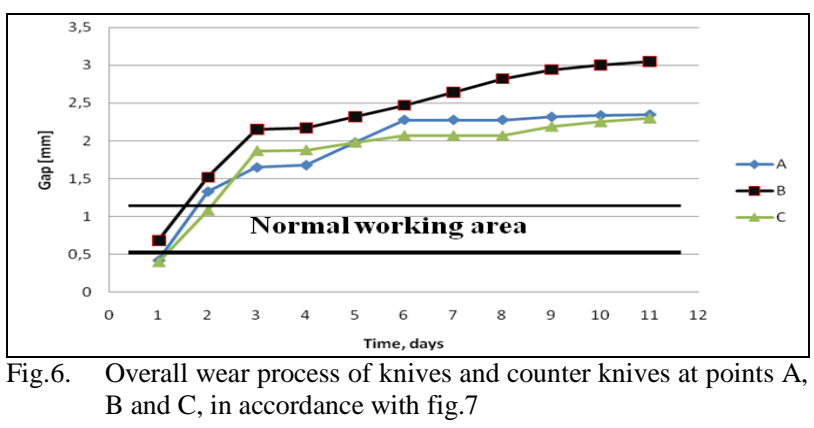

\section{FUTURE STEPS}

A hydraulic counter knife fastening support system will be developed for the middle of the shredder. Its purpose will be twofold: to support the counter knife fastening and to collect data on increased cutting force during the shredding process, by means of pressure sensors. The support system is shown in figure 7.

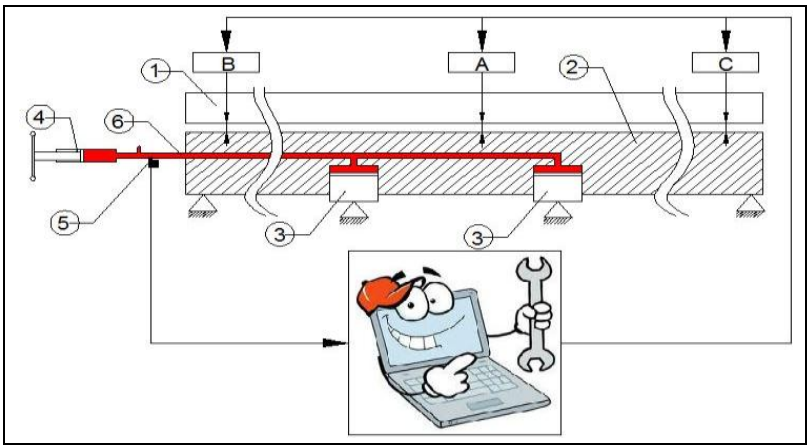

Fig. 7. Hydraulic support and measuring system scheme 
As stated above, the counter knife housing on the shredder construction is fixed only at either end, leaving the middle unsupported. Neither does the construction permit standard screw-in type support for stabilization. Accordingly, given these conditions it was decided to develop a support system inside the counter knife housing. The system's operation is based on two hydro cylinders (fig.7, 3), which are incorporated in the counter knife housing. The cylinders (fig.7, 3) can be pulled out by means of a screw piston (fig.7, 4). Their precision and necessary movement and holding force are defined by the difference between the working cylinder and controlling cylinder diameters. Also a fine thread in the controlling cylinder displacement mechanism helps regulate the process. Using this approach for screwing the controlling cylinder in and out, it is possible not only to support the counter knife outer shell, but also prevent any potential initial squirm. When adjusting the device, it is necessary to set the appropriate gap between the knife and counter knife in both constant support ends A and C (fig.7). The gap in the middle should be checked afterwards. If this gap is larger than at the ends, it is possible to reduce it by tightening the screw in the controlling cylinder (fig.7, 4) piston.

To avoid two separate systems for regulation and diagnostics, sensitive pressure sensors (fig.7, 5) are provided in the hydraulic system. The pressure sensor parameters are thoroughly described in reference [5].

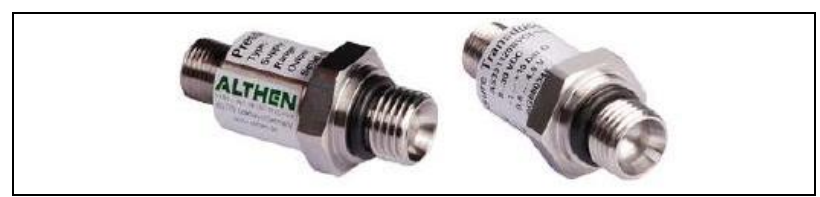

Fig.8. Pressure sensors

The range in which the pressure sensors should be engaged has not yet been established, as it involves a complex calculation system with too many output data variables. This consideration would lead to an imprecise system pressure oscillation range forecast. Therefore at the initial stage of support system elaboration, the working pressure oscillation range will be determined empirically. Only then will the appropriate pressure sensor be set up. The remaining data for this type of sensor is the same, as shown in table 2.

\begin{tabular}{|l|l|}
\hline Fatigue life: & $\begin{array}{l}\text { Designed for more than } 100 \\
\text { million cycles }\end{array}$ \\
\hline Long-term drift: & $\begin{array}{l}0.2 \% \text { FS/year (non- } \\
\text { cumulative) }\end{array}$ \\
\hline Accuracy of pressure output: & $0.25 \%$ FS \\
\hline $\begin{array}{l}\text { Accuracy of temperature output } \\
\text { (AS50 only): }\end{array}$ & $3.5 \%$ of temperature span \\
\hline Thermal error, typical: & $1.5 \% \mathrm{FS} / 100{ }^{\circ} \mathrm{C}$ \\
\hline Bandwidth: & $\begin{array}{l}\mathrm{AS} 30: \mathrm{DC} \ldots 250 \mathrm{~Hz} \\
\mathrm{AS} 50: \mathrm{DC} \ldots 1 \mathrm{kHz}\end{array}$ \\
\hline Compensated temperature range: & $-40 \ldots+105{ }^{\circ} \mathrm{C}$ \\
\hline Operating temperature range: & $-40 \ldots+105^{\circ} \mathrm{C}$ \\
\hline Zero tolerance: & $0.5 \%$ of span \\
\hline Span tolerance: & $0.5 \%$ of span \\
\hline Pressure port & see table below \\
\hline Wetted parts material: & $17-4$ PH stainless steel \\
\hline
\end{tabular}

By ensuring communication between the pressure sensor and computer, it will be possible to collect and analyse pressure oscillation data in the closed support system.

After full implementation and testing of the support system, pressure sensor synchronization has been scheduled, measured by the regular operator (fig.7, A, B, C), along with digital data flow readings. The summarized measurements of the knife and counter knife (fig.7, 1 and 2) gap will be correlated with the pressure sensor readings and used to develop a computerized system. The system will notify the operator of any increase in cutting forces, caused by knife wear or other reasons. The succesful development of such a system would be highly beneficial, as it would warn the operator about changes in the cutting process characteristic parameters, enabling him to take timely decisions concerning further actions.

In addition, automatic system shut-down should be introduced in the event that measured loads exceed the critical level and the operator fails to take any action. This service system will save financial resources by reducing expenditure on emergency repairs and replacing parts earlier than is necessary.

\section{CONCLUSIONS}

The aim of this paper is to briefly describe progress on the doctoral thesis and research results [6], performed during the course of its preparation

It offers a general insight into drum-type shredding machine construction, its working principles and significance in the overall manufacturing system.

The main operational problems are described, along with their potential causes.

The implemented improvements have been identified and their impact on cutting process characteristic parameters has been demonstrated by means of calculations.

Further work will be necessary for setup improvement and for the diagnostic system development.

The working principle of the hydraulic support system is described and preparation of this exact system has been proved.

The paper concludes with a description of the basic principles of the diagnostic-based service system. Based on successful experiments and improvements, this system will be developed and fitted on this specific shredder, and may potentially be suitable for use on other similar kinds of machines.

\section{REFERENCES}

[1] Бершадский А. Л. /Bershadsky A.L., (1975) Резание древесины/Wood cutting. Вышэйшая школа, Minsk

[2] J.P. Den Hartog, (1956) Mehanical vibrations, McGraw-Hill Book Company, ISBN: 0-486-60754-2, New York

[3] Technical documentation for RAUTE TR 1020-1300V chipping machine

[4] Tuherms H., (1985) Kokapstrādes instrumenti/Wood processing instrumentation. Zvaigzne, Riga

[5] Measurment and control sensors (12.08.2012.) [WWW], http://www.althensensors.com

[6] Zarins, M.; Torims, T. (2012) Diagnostic of drum type wood shredder machines, China, Taiyuan 